\title{
The Current Status of Research on English Language Teaching for Deaf Students - A Visual Analysis Based on CiteSpace Software
}

\author{
Zheng $\mathrm{Wu}^{1, *} \&$ Shaohua Jiang ${ }^{2}$ \\ ${ }^{1}$ Department of Linguistics and Translation, City University of Hong Kong, Hong Kong, China \\ ${ }^{2}$ School of Humanities, Fujian University of Technology, Fujian Province, China \\ *Correspondence: Department of Linguistics and Translation, City University of Hong Kong, Hong Kong, China. Tel: \\ 852-5165-7766. E-mail: zhengwu6-c@my.cityu.edu.hk
}

Received: December 17, 2020

Accepted: January 6, 2021 Online Published: January 9, 2021

doi:10.5430/ijelt.v8n1p11

URL: https://doi.org/10.5430/ijelt.v8n1p11

\begin{abstract}
This article is in line with the initiatives of "supporting the disadvantaged" and "developing the cause of persons with disabilities" proposed by UNESCO. With using "deaf students" and "English teaching" as the key research terms, efforts are put into searching research in the Web of Science (WOS) core collection database from the year 2000 to 2020 . The index results are sorted by publication years, authors, institutions, sources and keywords. Then these statistics are visualized by CiteSpace software in five aspects, including authors, institutions, journal sources and keywords. In total, there include 4866 articles abroad in this study. The number of articles published at home and abroad show an increasing trend. These collected researches focus on the teaching method, teaching strategy, cognitive condition, sign language teaching, and cochlear implant in English teaching for deaf students. The foreign ones emphasize on ability of deaf students themselves and influence force of auxiliary tool. The overall research on English language teaching for deaf students is on the rise, and the research contents and hot topics international literature are somewhat overlapped while somewhat different. The team cooperation and international exchange should be strengthened while complementing each other, in order to promote the overall development of this field.
\end{abstract}

Keywords: the deaf, English teaching, CiteSpace, foreign literature

\section{Introduction}

More than $5 \%$ the world's population, or 466 million people (432 million adults and 34 million children) suffer hearing loss. It is estimated that more than 900 million people (or one in ten people) will be subjected to hearing loss by 2050 (World Health Organization). Among them, there are about 20 million hearing impaired people in China, who enjoy the same right to access English education as the normal people. In the rapidly developing society, hearing impaired people can not only rely on their mother tongue for information, but also, they ought to read English materials to get the latest international information. In that, attending English classes helps hearing-impaired students to receive more up-to-date information about their professions and facilitates to meet their needs for further education and employment. Thus, learning English is not only beneficial for hearing-impaired students' further education and employment, but it is also their main channel for returning to mainstream society and embracing the world. However, there only 665,900 (Ministry of Education, China), less than a third of the total, have access to education. Among them, very few can have access to English. In response to the Second Phase of the Special Education Enhancement Plan (2017-2020) implemented by Ministry of Education, the needs of persons with disabilities are supposed to be met. During 70th years of protecting rights and interests of the disability, equality, participation, sharing, advocating special education and integrated education are advocated accordingly. Besides, this article presents the principles of vigorously promoting fairness in education and of rationally allocating educational resources, which lays a solid foundation for the special education (Lytle, Johnson, \& Hui, 2005). The purpose of this paper is to analyse the current state of research in the field of English language teaching for deaf students at abroad. To analyse the current research in the field of English language teaching for deaf student overseas. And it also plows a road for researchers to conduct in-depth research in this field. 
English education for hearing-impaired students at home has been carried out since the 1990s, which means that it only lasts for a short of period. Besides, the research on English education for hearing-impaired students is still in the blank stage now and the attention is also low. So, research in this aspect is in urgent need of in-depth attention and systematic investigation. But researchers often have a vague understanding of the field and are unable to follow the research developments in a timely manner (Rustamjonqizi, 2020). Under the current situation, there is an urgent need to summarize and analyze the literature. Meanwhile, scholars have committed to a lot of researches in this field, in order to realize the right to access equal education and help deaf students integrate into the society. They have been conducted on the ability level of deaf students, the teaching methods in classrooms, and the facilities and conditions of deaf schools (Tang, Adam, \& OBE, 2020). As a result of that, all these diverse research directions in this field make the relevant literature cover a big range and the links between different parts become complicated. Thus, it is of great importance to sort out the relevant literature in order to move further in this field and optimize the English education of deaf students. What's more, it is of practical significance in guiding the English discipline construction and in the improvement of English curriculum system (Dissake \& Atindogbé, 2019). It also benefits the construction and development of English teaching team for deaf students in special education. Review of past literature not only helps to promote the development of special education and improve the English education system for the hearing impaired, but also provides a mirror for the English teaching of the hearing-impaired students. This kind of review at the exploratory stage puts forward some new ideas for the study of English education for the hearing impaired.

CiteSpace (Chen, 2006) is an information-visualized software developed by Dr. Chao-Mei Chen, which has the dual features of "graph" and "spectrum". It can conduct a quantitative research towards literature in a specific field. And it can present the key points of computational measurement and visualization analysis, which makes it become an ideal tool for analysis. Then, CiteSpace is also an important tool for exploring hot topics and trends in target field. Therefore, this paper uses Citespace to analyze the recent research literature on English education for the hearing impaired. It aims to grasp the knowledge base of the field in terms of the number of publications, important authors or teams, research hotspots, research progress, and other aspects.

\section{Material and Methodology}

\subsection{Data Sources}

The Web of Science (WOS) core database is an important one for acquiring references in English, covering all countries. Considering that the CiteSpace software is highly applicable to the document formats in the WOS database, English literature is search in WOS.26.

\subsection{Research Standard}

The time span is set from January 1st, 2000 to August 1st, 2020. The English search terms is Subject= "deafness" and "English learning" OR "hearing loss" and "English education". Through retrieval, 4866 English documents is finally included after the filtering some repeated article through checking title and abstract.

\subsection{Research Methods}

The English bibliography is exported in "Other" format. Then this group of references is put into the CiteSpace 5.7. R1.

The Figure 1 is a screenshot of the main interface of this version. The main selected parameters are as shown in this figure. Specifically, the setting parameters include time partition for 2000-2020, time slice (Year Per Slice) for "1", node types for author, institution, keyword. The threshold (Top N per Slice) is set to 30, using Pathfinder clipping to simplify the graph (Ding \& Yang, 2020). The node size indicates its number of occurrences, and the line thickness between the nodes represents its degree of connection, so as to achieve the knowledge graph analysis of author, source, institution, keyword and other aspects of the literature.2.3.1 Sample Size, Power, and Precision 


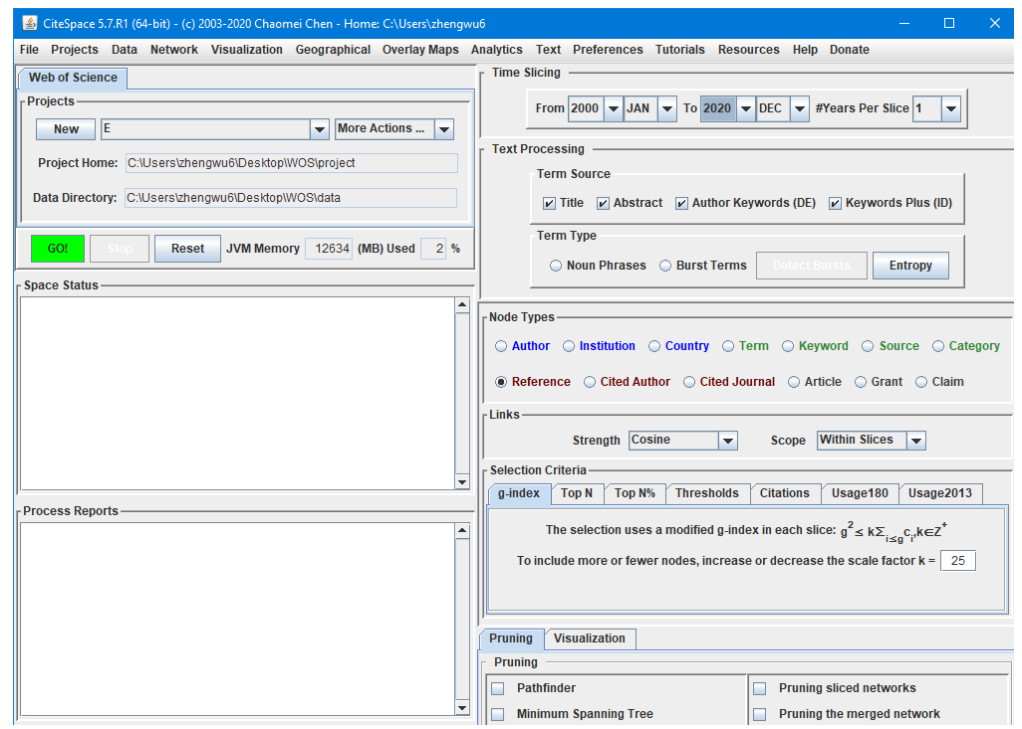

Figure 1. The Interface of CiteSpace

\section{Results}

\subsection{Tendency of Publication}

As shown in Figure 2, the number of publications on English education for deaf students has been increasing from 2000 to 2020 .

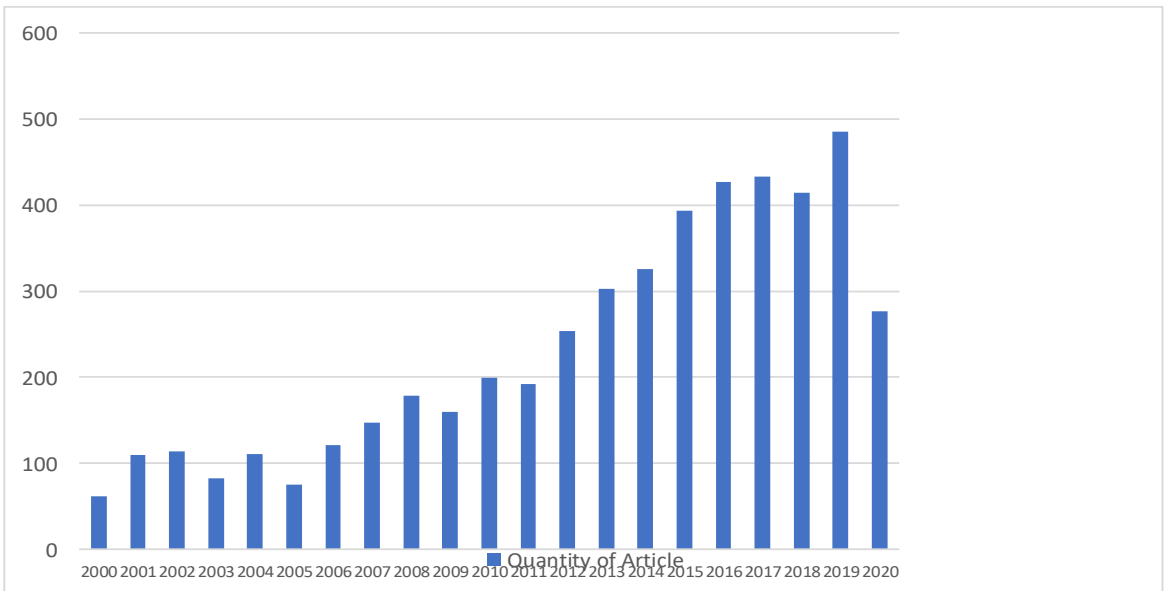

Figure 2. Annual Distribution of the English Teaching of the Hearing-impaired Students from 2000 to 2020

To be more exactly, there is a growing tendency in the number of English articles published from 2000 to 2011 in despite some fluctuations. After 2011, article volume presents a rapid rising overall. It is found that research in international regions is getting more and more attention. Meanwhile, the foreign study promotes the Chinese counterpart. As for the overseas publication, several fluctuations in the volume are more likely to be related to technological transformations. With the continuous process of technological optimization, the volume of literature on cochlear implants and proficiency testing has increased dramatically.

\subsection{Institution Distribution}

Using the "Institution" function in CiteSpace software, the result of analysing the issued country as shown in Table 1. 
Table 1. Top 10 Distribution of Core Country from 2000 to 2020

\begin{tabular}{cccc}
\hline Countries & Count & Centrality & Year \\
\hline USA & 2270 & 0.59 & 2000 \\
England & 437 & 0.29 & 2000 \\
Canada & 372 & 0.09 & 2000 \\
Australia & 363 & 0.11 & 2000 \\
People Republic of China & 256 & 0.04 & 2000 \\
Germany & 216 & 0.02 & 2000 \\
France & 189 & 0.08 & 2000 \\
Netherlands & 175 & 0.12 & 2000 \\
Spain & 168 & 0.09 & 2002 \\
Italy & 124 & 0.03 & 2001 \\
\hline
\end{tabular}

Drawn from the analysis of occurrence time of centrality, the top ten are all developed countries in terms of centrality. The United States enjoys the largest number of texts and the highest centrality while it detects the centrality at the earliest time. Although China is ranked fifth in the publication volume, its centrality is only 0.04 . This phenomenon shows that despite China is at the forefront of the number of studies on teaching English to deaf students, its influence in the international arena has yet to be further improved.

\begin{tabular}{|c|c|c|c|c|c|}
\hline Countries & Year & Strength & Begin & End & $2000-2020$ \\
\hline TURKEY & 2000 & 3.9095 & 2012 & 2013 & \\
\hline INDIA & 2000 & 3.4791 & 2015 & 2020 & \\
\hline INDONESIA & 2000 & 4.141 & 2017 & 2020 & \\
\hline POLAND & 2000 & 4.707 & 2017 & 2020 & \\
\hline SAUDI ARABIA & 2000 & 4.9702 & 2018 & 2020 & \\
\hline
\end{tabular}

Figure 3. Top 5 Countries with the Strongest Citation Bursts

The research on English language teaching for deaf students in these countries, seen in Figure 3, start relatively late. On the other side, their unique education system has aroused the wide attention in various countries and regions when many scholars in these countries have already invested their efforts and published influential articles in international journals.

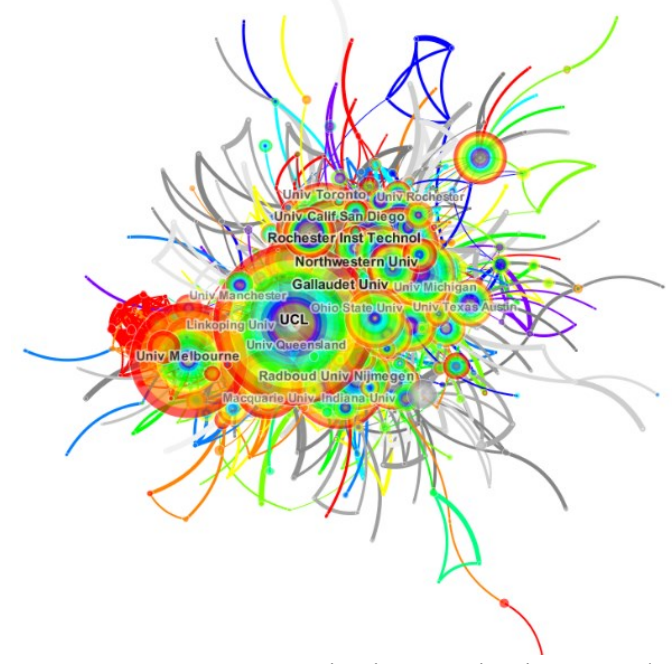

Figure 4. Co-citation Institution Graph 
Table 2. Top 10 Distribution of Domestic Institutions

\begin{tabular}{lll}
\hline Intuitions & Count & Year \\
\hline UCL & 112 & 2001 \\
Gallaudet University & 96 & 2001 \\
Northwestern University & 96 & 2003 \\
Rochester Institute of Technology & 95 & 2004 \\
University of Melbourne & 84 & 2004 \\
University of California San Diego & 81 & 2002 \\
Radboud University of Nijmegen & 69 & 2006 \\
University of Toronto & 69 & 2006 \\
University of Queensland & 62 & 2008 \\
University of Rochester & 60 & 2001 \\
\hline
\end{tabular}

By using the "Institution" function in CiteSpace software, all the issued institutions are analyzed, then followed by integrating all the secondary institutions. These two steps aim to obtain the ranking of major issuing institutions, as shown in Table 2 and Figure 4. It can be seen that the major publishers are comprehensive universities, with UCL ranking first. From the cooperation spectrum of institution, institution's relationship in different regions of China is scattered, and the network density is only 0.0004 . As for the foreign institutions, there are 525 institutions with 1526 connections, and the network density reaches to 0.0111 . Moreover, multiple sub-networks are connected to each other among these overseas institutions, which indicates the close cooperation exists. The practice of comparing distribution of domestic organization and that of foreign suggests that China should enrich the research institutions and strengthen the cooperation among them.

\subsection{Research Hotspot}

The "Keyword" function of CiteSpace software is used to obtaining the keyword map of domestic publications in English education for deaf students, see Figure 5. The high-frequent keywords and their corresponding word frequency is displayed in see Table 4. It can be included the hotspots of English teaching of deaf students in different periods and the patterns of research hotspots.

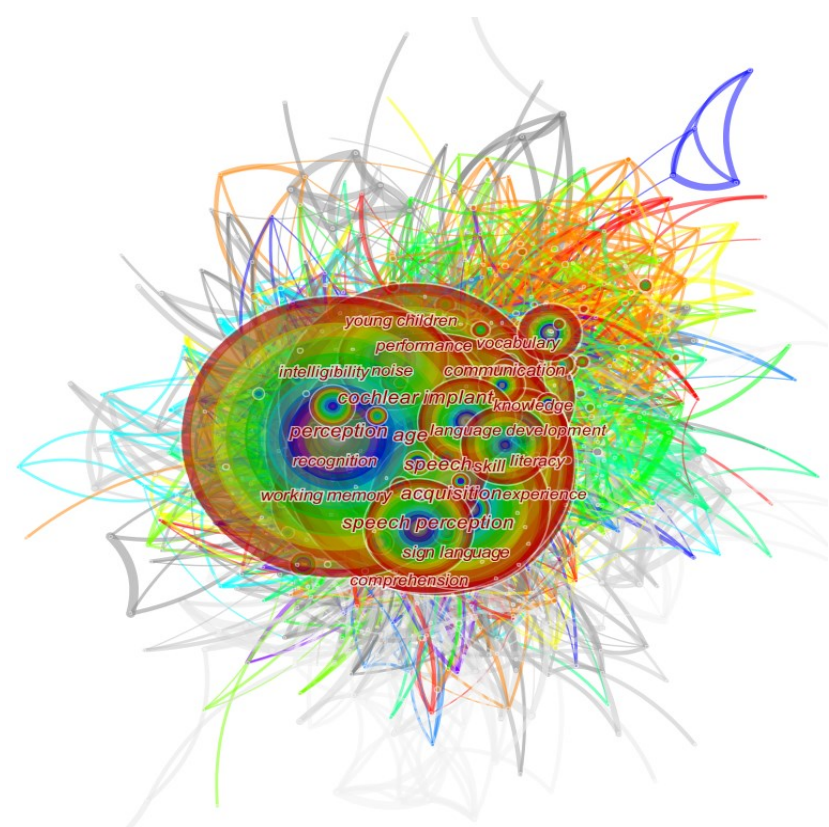

Figure 5. High-frequency Keyword Map from 2000 to 2020 
Table 4. High-Frequency Keywords from 2000 to 2020

\begin{tabular}{lll}
\hline Keywords & Count & Year \\
\hline perception & 543 & 2002 \\
age & 508 & 2000 \\
speech & 505 & 2000 \\
acquisition & 499 & 2000 \\
cochlear implant & 484 & 2000 \\
speech perception & 479 & 2002 \\
sign language & 334 & 2000 \\
skill & 321 & 2003 \\
communication & 262 & 2002 \\
working memory & 251 & 2002 \\
language development & 236 & 2002 \\
recognition & 228 & 2000 \\
performance & 225 & 2002 \\
comprehensive & 215 & 2002 \\
noise & 206 & 2004 \\
knowledge & 190 & 2002 \\
intelligibility & 185 & 2002 \\
vocabulary & 184 & 2004 \\
literacy & 180 & 2007 \\
experience & 161 & 2001 \\
young children & 161 & 2003 \\
\hline
\end{tabular}

The nodes in Figure 5 represent keywords, and lines reflect the coexistence of those keywords. The circle size represents the centrality degree of keyword, with larger circles indicating greater centrality and influence. Based on the Price law, the high-frequent words means the frequency equals or beyond 150. As seen from Table 4, there are 21 qualified words in the area of teaching English to the deaf. Among these words, the words "perception" and "acquisition" enjoy the highest frequency, which display that foreign scholars focus on the cognitive aspect of English teaching for deaf students and the scholars also pay great attention to design the scientific framework and rational. At the same time, the major breakthrough of core technology in the process of individual learning of deaf students is also emphasized. The general direction, framework and blueprint of the whole system play a decisive role in the smooth process of English language teaching for deaf students.

The design in the coming future should firstly ensure scientific characteristics, i.e., practical and operational features. Secondly, it should be better integrated with the learning environment, teacher and his or her practice, cultural norm, available resource, and student's daily life and learning task. In addition, foreign countries have been committed to improving the English teaching of deaf students in the field of technology breakthroughs, mainly in two main directions. The first one refers to optimization of cochlear implants. implants for different individuals. This is the first time that a deaf person has been able to use a personalized cochlear implant to improve hearing recognition, reduce the difficulty of classroom comprehension, and help improve the learning efficiency in general. And the second points to brain activity of every deaf student. With the help of fmri technology, the physiological changes are explored during English learning when individual students as the main subject. Putting the investigation into students of different learning efficiency, it can visualize the abstract concepts of English proficiency into empirical data on brain activity. It can draw from the empirical statistics extra help is supposed to be provided for students who need it. Students are made to be engaged and interested in learning while answering questions they may have, for optimizing classroom instruction. 


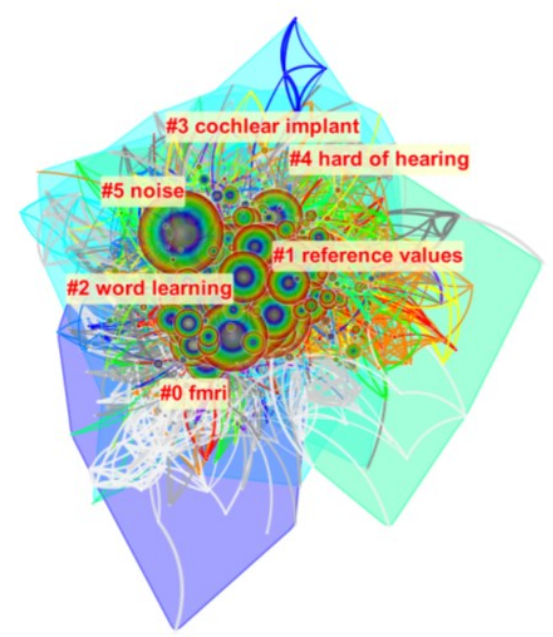

Figure 6. Keyword of LLR Clustering Knowledge Map from 2000 to 2020

The Cluster analysis of the keywords in the literature aims to clearly understand the research process in this field. Figure 6 shows the keywords cluster in foreign literature, showing 796 keywords and 8241 links. This figure shows that these keywords are closely related to each other. During the cluster development, the LLR algorithm is applied to group the labels. The cluster module $\mathrm{Q}=0.3607$ suggests that the cluster structure is significant, which can clearly define boundary of the research direction in six clusters.

The keywords contained in the different clusters are analyzed and then summarized to specific research theme. The Figure 6 displays the result of keyword cluster based on LLR principle. Specifically, the cluster 0 stands for research techniques used in the study, 1 for the number of references needed in the experiments when comparing research methods, 2 for the foundation of English teaching with starting with teaching single word. The 3 cluster represents technological aids so that students can grasp a better understanding of what they are taught while cluster 4 for the problems and obstacles. And the cluster 5 means the external hindrances. All these cluster indicates that foreign research on English teaching for deaf students is rich and hierarchical.

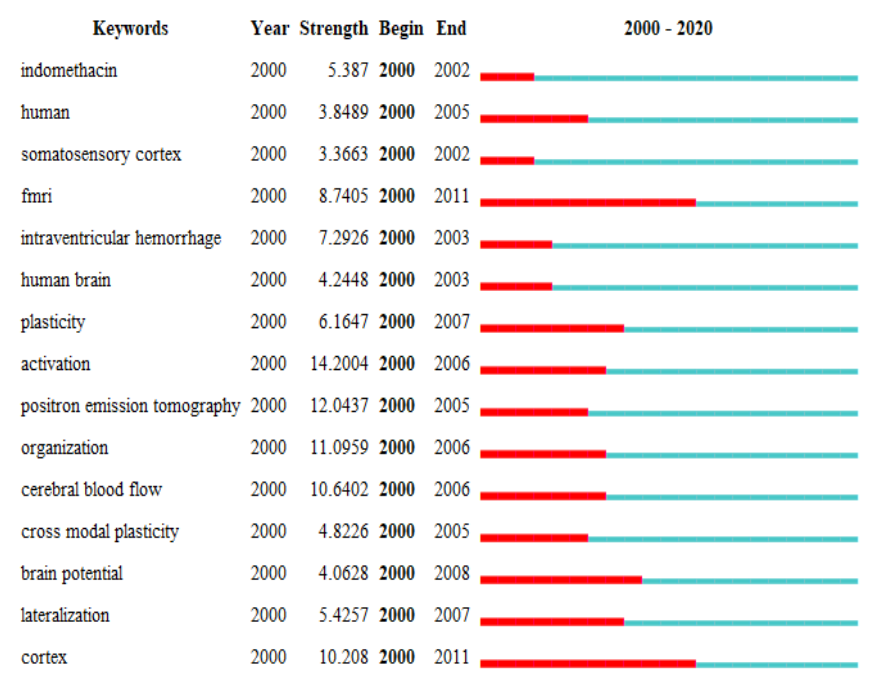

Figure 7. Top 15 Keywords with the Strongest Citation Bursts

The "Burst" function of CiteSpace V software can dig out the value of relevant research in related fields. And this function also provides a reference for the development trend and frontier detection in the target field. In this paper, the software is used to perform burst detection on the collected samples, and then a total of 10 major burst words are 
screened out, see Figure 7.

As seen in Figure 7, it can be found that the keywords about deaf students have high burst intensity, and most of them have a burstiness duration of two years or more. These burst situations constitute the important part of the English teaching on deaf students in different periods. Among this, the burstiness of keywords "fmri" and "cortex" have lasted for 11 years. Against the background of the rapid technology development, the use of high-end equipment are the most important components of the study. Exploring the changes within the body of deaf student during learning English process has been a continuing focus and interest of the academic community.

Under this theme, solving the problem of how to stick to the starting point of moral education is the essential part of the deep digging practice. Based on educational practice, together with innovating the ways and methods of teaching, will be the frontier trend and the main direction of research in this field in the future.

Although most of the current research is limited to "instrumental" thinking and the theory is more theoretical than practical refinement, we can still have a macro grasp of the theme, frontier and future research direction of English teaching for the deaf in recent years through the processing of CiteSpace. Teaching English to the deaf is a dynamic and systematic project. Only through in-depth study of its content and contents, innovative educational channels and evaluation methods, and the construction of a scientific and effective professional ethics education system can we truly enhance the deaf students' professional identity and sense of responsibility and improve their ability to serve society.

\subsection{Co-citation Cluster Knowledge}

The Figure 8 shows the knowledge map of literature co-citation by using the visualization function. The color blocks at the top of the figure cover the range of 2000-2020 sliced by year. With the color shifting from warm to cool from left to right, the warmer tones point to the more recent. Each node in this figure represents a piece of literature, and the connecting line between nodes refer to a co-citation relationship between articles. In addition, the color of the connecting lines corresponds to the color block at the top of the figure, indicating the time of citation occurred. The circle around the node is actually the specific cited year, which can reflect the literature cited frequency. The larger the circle is, more frequent this article is cited. The color of the circle and the top of the color block both correspond to the literature-cited time. The dark color exists in the inner circle while the bright one in the outer circle. Some of the circles have purple circles on the periphery, which can reflect the value of the node's Betweenness Centrality in the map. Certain literatures serve as the vital part linking others, with the relatively high centrality. The analysis of this literature co-citation can give a glimpse into the development and extension of the field research. In addition, there are also some circles with bright red areas, indicating the Citation Burstness (CB) of that literature within these circles. Specifically, CB index reflects that one document is suddenly cited in a certain period, so that this burst phenomenon can reflect the hotspot of research. The size of the bright red area reflects the strength of the CB, and the position of this area within the citation year cycle demonstrates the time when the citation spike occurred. The black font label near each node shows the author and publication's year of the literature. In order to make the graph legible, Figure 8 only exhibits the labels that are cited more frequently than 200 times.

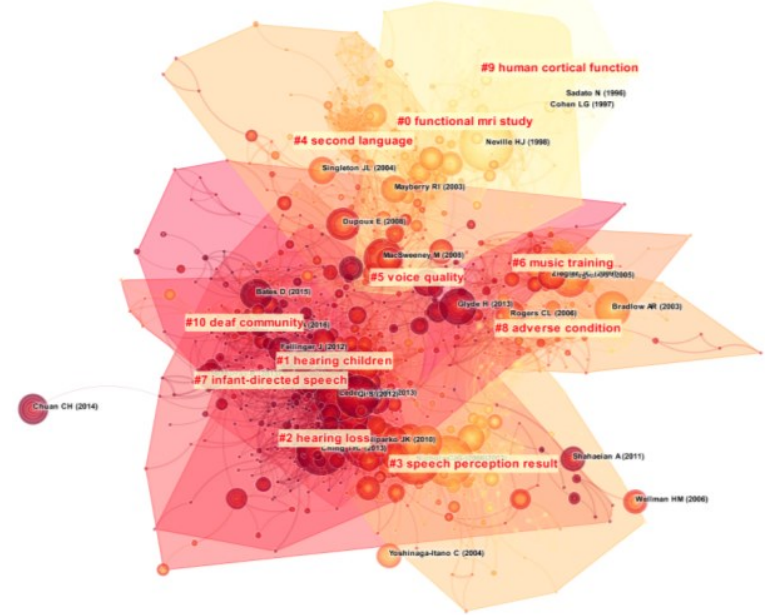

Figure 8. Co-citation Knowledge Graph

After forming cluster of co-citation knowledge graph of literatures, it is found that literatures within the same cluster 
are more closely related, which can be seen as having similar research theme. The Figure 8 shows 11 clusters obtained by cluster analysis and they are labeled respectively as clusters \#0 to \#10. The number of articles contained in cluster 0 to cluster 10 decreases with sequence.

The title of one article is an obvious indicator to the content, direction and method of the literature. The title is more complete than the keywords and it is also more concise than the abstract. Taking all the factors into consideration, this study uses the default LLD algorithm to analyze the keywords of the literature. All the cluster labels are shown in Figure 8. Each cluster is automatically assigned a label with red. The CiteSpace provides several algorithms and methods for label generation, including LSI, LLD (default), and MI (Zhiqiang \& Shaorui, 2015). For the classification, the object of analysis can be the title, keywords, and abstract.

The cluster label to a certain extent means the research direction and characteristics of cluster. However, further analysis of the actual situation of each cluster is needed to explore each cluster in depth. Table 5 shows the main parameters of the 11 major clusters, and all the data in the Table 5 correspond to what in Figure 8. The cluster size shows the number of articles contained in this cluster. The Silhouette is the contour value of the cluster, reflecting the clustering result. Specifically, the closer the value is to 1 , the better the cluster effect is. The average year of the documents reflects the average year of publication within that cluster.

Table 5. Literature Clustering Result

\begin{tabular}{ccccc}
\hline Number & Size & Silhouette Value & average year & clustering label \\
\hline 0 & 174 & 0.881 & 2000 & functional mri study \\
1 & 170 & 0.829 & 2011 & hearing children \\
2 & 138 & 0.818 & 2012 & hearing loss \\
3 & 137 & 0.905 & 2002 & speech perception result \\
4 & 96 & 0.919 & 2003 & second language \\
5 & 82 & 0.939 & 2012 & voice quality \\
6 & 65 & 0.933 & 2007 & music training \\
7 & 64 & 0.894 & 2011 & infant-directed speech \\
8 & 53 & 0.976 & 2005 & adverse condition \\
9 & 49 & 0.975 & 1996 & human cortical function \\
10 & 39 & 0.971 & 2010 & deaf community \\
\hline
\end{tabular}

As a largest one of the 11 clusters, the 0 -cluster containing 174 articles and many highly cited articles also appear in this cluster. The approaches of teaching English to deaf students are directly reflected in several pieces within that cluster. The most representative article (Neville et al., 1998) combined with the highest count one (MacSweeney, Capek, Campbell, \& Woll, 2008) use fmri and PET techniques within the field of neuroimaging. Both two articles study brain activity of the deaf students during English learning and their stimulation of brain responses by the teaching of sign language, with a wide impact in the academic community.

The cluster 1 is labelled as "hearing children", containing 170 documents. It is second in size only to cluster 0 , which also contains many highly cited articles. The cluster 1 focuses on deaf children, which fits well with its label (Lederberg, Schick, \& Spencer, 2013; Qi \& Mitchell, 2012). The cluster 2 "hearing loss" emphasizes the impact of deaf children's deficits on long-term language learning (Ching et al., 2013). And it also shows the role played by cochlear implants (Niparko et al., 2010). The "speech perception result" of cluster 3 stands in a combination of quantitative and qualitative research, especially on the cognitive outcomes of language during learning (Geers, Nicholas, \& Sedey, 2003; Nicholas \& Geers, 2006). In addition, it is not surprising to find that cluster 5 "voice quality" is a study of the input sounds heard by deaf individuals as well as the output sounds of the spoken. In line with the cluster 3, the Ccuster 4 points to the diversity in the selection of experimental subjects. Meanwhile, this cluster also includes the teaching English as a second language to deaf students, in addition to the study of English as a native language, shifting the focus from native language to second one (Mayberry \& Lock, 2003; Nicholas \& Geers, 2006). The articles in this cluster literature also have a large degree of burst. Then the cluster 6 refers to "music training". It brings the disruptive effect of "noise" and then assesses deaf student's listening comprehension, to explore deaf student's response to the stimulus noise (Glyde, Cameron, Dillon, Hickson, \& Seeto, 2013). The cluster 7 begins with the infant in the early stages of language development. This kind of research land on precisely these deaf infant (McMurray, Kovack-Lesh, Goodwin, \& McEchron, 2013) perceptions of phonological unit, phonemes 
(Dupoux, Sebastián-Gallés, Navarrete, \& Peperkamp, 2008). The cluster 8 "adverse condition", the cluster 9 "human cortical function", and the cluster 10 "deaf community" all enjoy high Silhouette values, indicating that the nodes in these three clustered networks are highly homogeneous.

\subsection{Potential Research Hotspot}

The following clustering timeline diagram can be obtained, by using of the CiteSpace's Timeline View function. The timeline diagram can visually show the evolution of each cluster over time. It can be seen that the key node literature is mainly concentrated in the first five clusters $(\# 0-\# 4)$, which indicates that these clusters are dominant in the teaching of English to deaf students. In terms of timeline evolution, the cluster 1 and the cluster 5 are still evolving. The cluster 0 and cluster 8 , whose nodal links are mostly yellow, present that the co-citation of literature in two cluster is more recent, for forming an emerging research direction. On the other hand, the cluster 9 and the cluster 10 have less variation in the time interval selected in the study. In the study of English language teaching for the deaf, the research paradigm of combining speech perception, hearing impairment and hearing loss in deaf children is common. What's more, the two major concerns are the sound heard or made by hearing impaired people including young children. Then, the use of medical fmri techniques to investigate brain activity and learning disadvantages in deaf children may be an emerging interest.

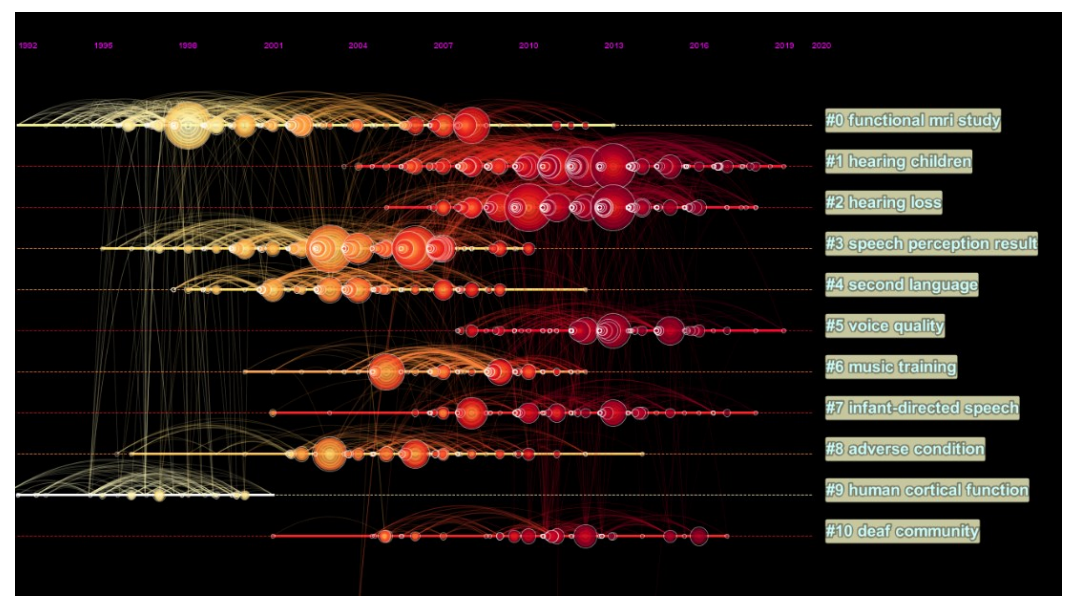

Figure 9. The Citation Knowledge Graph Presented in Timeline
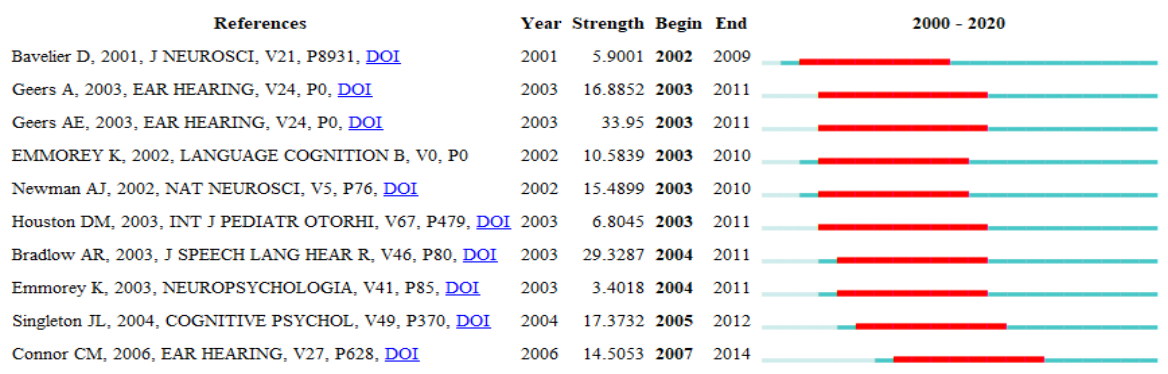

Figure 10. Latest Literature with High Citation Burstness Value

\section{Discussion}

This paper analyses the relevant literature data through the method of bibliometric research, to investigate the current research status and development tendency in terms of English teaching for deaf students. At the same time, this paper tries to explore research hotspots in that aspect and points out the existing problems and solutions. Through the above-mentioned analysis, it finds that the research articles on English teaching for deaf students are increasing year by year. And various stable scientific research teams are formed.

In that research field, the research paradigm of targeting the deaf children group, of offsetting the hearing impairment, 
and of speech-perception combination embrace great popularity. The research on English education of the deaf grows with the times, and it gradually possess the interdisciplinary, experimental and open characteristics. The sounds heard and uttered by hearing impaired people, especially the young children at the immature stage, are the major research topic with more attention. In the coming future, exploring the disadvantages within brain activities of the deaf during learning process, by use of medical fmri technology, is more likely to be an emerging hot topic. Meanwhile, the multiple complementarities of research methods also need a lot of efforts from scholars.

\section{Acknowledgements}

Acknowledgment I would like to express my sincere gratitude and appreciation to my admirable supervisor Professor LIU for her continuous support throughout my article, for her endless patience, kindness, motivation, immense knowledge, guidance and expertise.

\section{References}

Chen, C. (2006). CiteSpace II: Detecting and visualizing emerging trends and transient patterns in scientific literature. Journal of the American Society for information Science and Technology, 57(3), 359-377. https://doi.org/10.1002/asi.20317

Ching, T. Y., Dillon, H., Marnane, V., Hou, S., Day, J., Seeto, M., ... Van Buynder, P. (2013). Outcomes of early-and late-identified children at 3 years of age: findings from a prospective population-based study. Ear and hearing, 34(5), 535. https://doi.org/10.1097/AUD.0b013e3182857718

Ding, X., \& Yang, Z. (2020). Knowledge mapping of platform research: a visual analysis using VOSviewer and CiteSpace. Electronic Commerce Research, 1-23. https://doi.org/10.1007/s10660-020-09410-7

Dissake, K. M. E., \& Atindogbé, G. G. (2019). Deaf education and Language-Based Curriculum: The case of the Buea School for the Deaf. Presented on the $9^{\text {th }}$ Pan-Commonwalth Forum, Oasis, 2019.

Dupoux, E., Sebastián-Gallés, N., Navarrete, E., \& Peperkamp, S. (2008). Persistent stress 'deafness': The case of French learners of Spanish. Cognition, 106(2), 682-706. https://doi.org/10.1016/j.cognition.2007.04.001

Geers, A. E., Nicholas, J. G., \& Sedey, A. L. (2003). Language skills of children with early cochlear implantation. Ear and hearing, 24(1), 46S-58S. https://doi.org/10.1097/01.AUD.0000051689.57380.1B

Glyde, H., Cameron, S., Dillon, H., Hickson, L., \& Seeto, M. (2013). The effects of hearing impairment and aging on spatial processing. Ear and hearing, 34(1), 15-28. https://doi.org/10.1097/AUD.0b013e3182617f94

Lederberg, A. R., Schick, B., \& Spencer, P. E. (2013). Language and literacy development of deaf and hard-of-hearing children: Successes and challenges. Developmental psychology, 49(1), 15. https://doi.org/10.1037/a0029558

Lytle, R. R., Johnson, K. E., \& Hui, Y. J. (2005). Deaf education in China: History, current issues, and emerging deaf voices. American Annals of the Deaf, 150(5), 457-469. https://doi.org/10.1353/aad.2006.0009

MacSweeney, M., Capek, C. M., Campbell, R., \& Woll, B. (2008). The signing brain: the neurobiology of sign language. Trends in cognitive sciences, 12(11), 432-440. https://doi.org/10.1016/j.tics.2008.07.010

Mayberry, R. I., \& Lock, E. (2003). Age constraints on first versus second language acquisition: Evidence for linguistic plasticity and epigenesis. Brain and language, 87(3), 369-384. https://doi.org/10.1016/S0093-934X(03)00137-8

McMurray, B., Kovack-Lesh, K. A., Goodwin, D., \& McEchron, W. (2013). Infant directed speech and the development of speech perception: Enhancing development or an unintended consequence? Cognition, 129(2), 362-378. https://doi.org/10.1016/j.cognition.2013.07.015

Neville, H. J., Bavelier, D., Corina, D., Rauschecker, J., Karni, A., Lalwani, A., ... Turner, R. (1998). Cerebral organization for language in deaf and hearing subjects: biological constraints and effects of experience. Proceedings of the National Academy of Sciences, 95(3), 922-929. https://doi.org/10.1073/pnas.95.3.922

Nicholas, J. G., \& Geers, A. E. (2006). Effects of early auditory experience on the spoken language of deaf children at 3 years of age. Ear and hearing, 27(3), 286. https://doi.org/10.1097/01.aud.0000215973.76912.c6

Niparko, J. K., Tobey, E. A., Thal, D. J., Eisenberg, L. S., Wang, N.-Y., Quittner, A. L., \& Team, C. I. (2010). Spoken 
language development in children following cochlear implantation. Jama, 303(15), 1498-1506. https://doi.org/10.1001/jama.2010.451

Qi, S., \& Mitchell, R. E. (2012). Large-scale academic achievement testing of deaf and hard-of-hearing students: Past, present, and future. Journal of Deaf Studies and Deaf Education, 17(1), 1-18. https://doi.org/10.1093/deafed/enr028

Rustamjonqizi, N. N. (2020). Psychological condition of deaf children in teaching English. ACADEMICIA: $A n$ International Multidisciplinary Research Journal, $10(5), \quad 304-307$. https://doi.org/10.5958/2249-7137.2020.00355.9

Tang, G., Adam, R., \& OBE, K. S. (2020). Educating bilingual and multilingual deaf children in the 21 st century. Understanding Deafness, Language and Cognitive Development: Essays in honour of Bencie Woll, 25, 183. https://doi.org/10.1075/tilar.25.10tan

Zhiqiang, D., \& Shaorui, Z. (2015). Hotspot Domains and Frontier Topics of Chinese Special Education: Based on Knowledge Mapping of Key Words of "Chinese Journal of Special Education" Published in Recent ten years. Education Research Monthly, 2, 3.

\section{Copyrights}

Copyright for this article is retained by the author(s), with first publication rights granted to the journal.

This is an open-access article distributed under the terms and conditions of the Creative Commons Attribution license (http://creativecommons.org/licenses/by/4.0/). 